\title{
Effect of Male Planting Date and Female Plant Population on Hybrid Maize Yield and Evaluation of Use of Hybrid-Maize Simulation Model for Grain Yield Estimation in Hybrid Maize Seed Production
}

\author{
Lennin Musundire ${ }^{1}$, Shorai Dari ${ }^{2}$, John MacRoberts ${ }^{1}$, H. S. Yang ${ }^{3}$, John Derera ${ }^{4} \&$ Pangirayi Tongoona ${ }^{4}$ \\ ${ }^{1}$ International Maize and Wheat Improvement Center (CIMMYT), Harare, Zimbabwe \\ ${ }^{2}$ Crop Science Department, University of Zimbabwe, Harare, Zimbabwe \\ ${ }^{3}$ Department of Agronomy and Horticulture, University of Nebraska-Lincoln, USA \\ ${ }^{4}$ African Centre for Crop Improvement, University of KwaZulu-Natal, Scottsville, South Africa \\ Correspondence: Shorai Dari, Department of Crop Science, University of Zimbabwe, P.O. Box MP167, Mt \\ Pleasant, Harare, Zimbabwe. Tel: 263-772-961-616. E-mail: shoraidari@yahoo.co.uk
}

Received: November 8, $2017 \quad$ Accepted: January 7, $2018 \quad$ Online Published: February 15, 2018

doi:10.5539/jas.v10n3p333 URL: https://doi.org/10.5539/jas.v10n3p333

The research was financed by CIMMYT.

\begin{abstract}
The study was carried out to determine the effect of male planting date (MPD) and female plant population (FPP) on the grain yield (GY) performance of a three-way hybrid and to evaluate Hybrid-Maize simulation model for grain yield estimation in hybrid seed maize production. Fifteen treatment combinations of five MPD as a deviation from the female planting date and three FPP replicated three times were used. The Hybrid-Maize simulation model programme was used to forecast the possible GY outcomes for the fifteen treatments of the experiment using estimated parameters and weather data for the 2006/7 season. The field experiment produced significant $(\mathrm{P}<0.005)$ main effects but non-significant interaction effects for GY, yield components and antheis-silking interval (ASI). Female seed yield was affected by time of male pollen shed relative to female silking: ASI, with highest yields associated with close synchrony (ASI $=+/-3$ days). ASI had a significant effect on the number of kernels per ear (KPE), with the greatest KPE (318) associated with an ASI of +/-3 days. FPP effects on yield are typical for maize, showing a curvilinear response from low to high density. The optimum population density for GY was 5.4 plants $\mathrm{m}^{-2}$. Simulation output from the Hybrid-Maize simulation model showed an overestimation of GY compare to the observed yield. Furthermore, the model was unable to predict yields for the low FPP of 2.7 plants $\mathrm{m}^{-2}$. We found that Hybrid-Maize simulation model has limited potential for simulating hybrid maize seed production, as it does not accommodate limitations that may occur during the growing season: difference in male and female planting dates, pollen density and dispersion. Hence, the fixed parameters for the Hybrid-Maize simulation model can only be used in maize commercial production.
\end{abstract}

Keywords: maize, male planting date (MPD), female plant population (FPP), grain yield (GY), Hybrid-Maize simulation model

\section{Introduction}

Maize hybrid seed is a source of subsistence, an embodiment of technological change and vital input for commercial maize agricultural production (Tripp, 2001). A response to the expected rise in demand for maize is inevitable according to a report by Rosegrant et al. (1995). World demand in 2020 is predicated to rise to about $138 \%$ of the 1995 demand. Given the limited opportunities for augmenting maize area in most countries, future output growth must come from intensifying production on current maize land. Shortage of maize hybrid seed in southern Africa is a major challenge considering efforts underway to increase maize production (Havazvidi \& Tatterfied, 2006). Seed production and distribution is currently associated with reduced production base, poor seed quality, increased marketing outlets and increased marketing costs. Therefore there is the need to have increased yield per unit land area to sustain the market as well as to offset costs. 
In hybrid maize seed production, grain yield is closely associated with kernel number at harvest (Andrade et al., 1999). Kernel number per plant is the most important aspect of grain yield in seed production because it determines the volume of hybrid seed maize that is produced per unit land area. Therefore, understanding the mechanisms that determine the volume of hybrid seed maize is important to maize physiologists, modelers and breeders in the development of production systems and models that aim to increase hybrid seed maize production. Accurate simulation models provide an important vehicle of estimating kernel number per plant in hybrid maize seed production.

According to Yang et al. (2006) forecasting of grain yield performance is important for several reasons: seed producers use such predictions for evaluating drought risks, helping to guide in-season adjustments to crop management, and to provide additional information to crop marketing decisions. Furthermore, major grain producers utilize yield forecasts to refine seed purchasing plans and politicians, insurance agencies and financial institutions may wish to predict farm income. Simulation models can be used to integrate the interaction of various physiological and abiotic factors that affect kernel number in maize and therefore are useful for predicting seed maize grain yields. Model predictions of grain yield per plant are generally based on empirical relationships between final kernel number and carbohydrate supplies or plant growth at silking, plant density and the radiation intercepted by the crop during the critical period bracketing flowering (Lizaso et al., 2003). In addition, final kernel production per hectare can also be simulated fairly accurately under pollen-limited conditions from simple measures of pollen shed and silking dynamics (Fonseca et al., 2004). This model assumes that pollination, which is followed by fertilization and kernel formation, is the limiting stage in kernel set and kernel production under optimum conditions. This assumption might apply to typical commercial maize production in some cases, but the number of fertilized ovules can limit kernel yield in a wide array of circumstances.

However, according to Carcova et al. (2002), pollination has been found not to limit kernel set under commercial hybrid maize production. The amount of pollen produced per plant could become a limiting factor for kernel number. In hybrid seed production, pollen production could be particularly important in certain specific production systems, where only a small proportion of plants (usually less than 20 percent) are used as pollinators (male lines). In these situations, knowledge of pollen production dynamics becomes essential for assessing the proportion of pollinating plants in the population needed for maximum kernel set. A short ASI is a key trait for obtaining high grain yield in maize seed production (Sarquis et al., 1998) and appears to result in a synchronous pollination among ovaries within and between ears. This has been reported to increase grain yield of different maize genotypes cropped at contrasting plant densities in different environments (Carcova et al., 2002). In contrast, plant density has been recognized as a major factor determining grain yield per plant (Andrade et al., 2002). Reduction in grain yield may be the result of lower numbers of ears (barrenness), lower kernel weight or a combination of these components. In dense populations, most of the ears may not develop. This occurs in some genotypes due to poor pollination resulting from delayed silking compared to tassel emergence and or due to limitation in assimilate supply that causes kernel and ear abortion. Crop models such as CERES-Maize (Jones \& Kiniry, 1986) and Hybrid-Maize (Yang et al., 2006) have been used to predict seed number and can dynamically evaluate optimum planting densities with different soils, different rainfall conditions and different maize hybrids.

This study establish whether Hybrid-Maize simulation model could be used in hybrid seed maize production to estimate grain yield by using a male inbred line and a female single cross as parents in hybrid formation. Comparison of the estimated grain yield from the simulation model and the actual yield determined the accuracy of the model. We hypothesized that maize grain yield will decrease with late planting and increased plant density as a result of reduced intercepted photosynthetically active radiation (IPAR) per plant and asynchrony between pollen shed and silking and that Hybrid-Maize simulating model can be used to predict grain yield in hybrid seed maize production. More so, this simulating model has the potential for optimising management practices in hybrid maize seed production and that appropriate parameters for the Hybrid-Maize simulation model may be determined for the male and female components of a seed field.

The objectives of the study were to i) determine the effects of maize plant density and male and female planting dates on ASI and maize grain yield in maize seed production using a male inbred line and a female single cross as parents in hybrid formation, and ii) simulate maize grain yield production for hybrid seed production using the Hybrid-Maize simulation model using the parameters: ASI, population density, planting dates and weather data so as to compare predicted yield and actual grain yield. 


\section{Materials and Methods}

\subsection{Genetic Materials}

Parents of a CIMMYT three-way hybrid (CML395/CML444//CML443) were used in this research: single cross female parent (CML395/CML444) and an inbred male parent (CML443). The experiment was laid out according to a $5 \times 3$ two-way factorial arrangement in a Randomised Complete Block Design (RCBD). Treatments consisted of fifteen treatment combinations of first factor: five male planting dates (MPD) as a deviation from the female planting date (FPD) and second factor: three female plant populations [26,666 plants ha ${ }^{-1}$ (low), 53,333 plants ha ${ }^{-1}$ (medium) and 80,000 plants ha ${ }^{-1}$ (high)]. The treatments were assigned randomly within blocks, with each treatment appearing once per block. The number of blocks was used as replications in which three replicates were used to produce 45 plots for the experiment.

A female: male planting ratio of $3: 1$, which is commonly used in seed production, was used in this trial. Each plot occupied $66 \mathrm{~m}^{2}$ with border rows surrounding the block and border plots separating plots to minimize cross-pollination across the block and within the plots respectively. The experiment was isolated by distance and time to ensure that there was no cross pollination with adjacent fields. Detasselling of female single cross was done before they started shedding pollen: when the top 3-4 $\mathrm{cm}$ of the tassel were visible above the whorl and this continued on a daily basis until complete. Shoot begging of the female single cross ears was also carried out and shoot begs were only removed on plots where the male lines were shedding pollen to ensure that the pollen was coming from the specific male inbred line within a plot. The ears were covered back with the shoot bags as soon as the male line had reached complete anthesis stage per plot. Therefore, the source of pollen was only the specific male line within a given plot. Shoot begs were eventually removed after the silks had dried off and the ears were allowed to reach field maturity before harvesting commenced.

\subsection{Field Management}

Ploughing was carried out using a tractor-drawn heavy disc plough in September 2006 at CIMMYT-Harare Research Station. A pre-marked wire was used to mark planting stations at spacing of $0.75 \mathrm{~m}$ between rows and $0.25 \mathrm{~m}$ within rows $4 \mathrm{~m}$ in length. Two seeds were sown by hand per planting hill and seedlings were thinned per planting hill four weeks after planting to achieve the three plant densities of 2.7 plants per $\mathrm{m}^{2}$ (26,666 plants per hectare), 5.3 plants per $\mathrm{m}^{2}$ (53,333 plants per hectare) and 8.0 plants per $\mathrm{m}^{2}(80,000$ plants per hectare).

A basal fertilizer application of $400 \mathrm{~kg} /$ ha of compound D fertilizer $\left(8 \% \mathrm{~N}: 14 \% \mathrm{P}_{2} \mathrm{O}_{5}: 7 \% \mathrm{~K}_{2} \mathrm{O}\right)$ was broadcast and disc-incorporated by a tractor. Topdressing was split applied using ammonium nitrate $(34.5 \% \mathrm{~N})$ : first application of $200 \mathrm{~kg} / \mathrm{ha}$ was done at four weeks after crop emergence soon after thinning and the second, also of $200 \mathrm{~kg} / \mathrm{ha}$ was done six weeks after crop emergence. The trial was mainly rain-fed, however, irrigation water was applied when necessary, for example, under dry planting to facilitate germination and in the case of a long dry spell. Irrigation scheduling was determined by the stage of development of the plants and temperature. In general, an irrigation of seven $\mathrm{mm} / \mathrm{hr}$ for six hours was applied just after planting to facilitate germination and thereafter irrigation interval ranged from 9 to 15 days depending on crop stage of development and temperature.

\subsection{Trait Measurements}

Measurements of variables: plant population density, planting dates of male line and female single cross, days to anthesis (DA), days to silking (DS), grain yield components and root lodging, were carried out in the net plot: three central female rows. The measurements were carried out at various stages of development and the data was used in the Hybrid-Maize simulation model as input data and also for general Analysis of Variance (ANOVA) for estimating potential yield and assessing the actual data.

\subsection{Hybrid-Maize Simulation Model}

Running the Hybrid-Maize simulation model in yield forecasting mode allowed real-time, in-season simulation of maize growth up to the date of simulation run, and also allowed forecasting of the possible outcome in final yield based on the up-to-date weather data of the current growing season, supplemented by the previously collected historical weather data for the University of Zimbabwe farm. Yield forecasts were made until the last day of the 2006-7 seasons in the weather file. To use the yield-forecasting mode, a weather data file containing 17 years of reliable historical weather data [year, day, solar $\left(\mathrm{MJ} \mathrm{m}^{-2}\right)$, temperature-high $\left({ }^{\circ} \mathrm{C}\right)$, temperature-low $\left({ }^{\circ} \mathrm{C}\right)$, relative humidity (\%), and rainfall $(\mathrm{mm})]$ was used, in addition to weather data for 2006-7 seasons. Hybrid-Maize simulation model could not separate difference in male and female planting dates. Hence, female planting dates (FPD) were used to run the programme. 


\subsection{Statistical Analysis}

Analysis of variance (ANOVA) for grain yield components was performed using Agro-base GII Statistical Package (Agronomix Software Inc., 2007). A general linear model was used for the analyses of variance.

\section{Results}

An analysis of variance of the main effects of MPD and FPP, and the interaction of MPD and FPP for the following traits: DS, DA, ASI, EPP, plant density (PD), harvest density (HD), ear density (ED), kernels per ear (KPE), thousand kernel weight (TKW) and grain yield (GY) data is presented in (Table 1). There was no significant effect of MPD, FPP and the interaction between MPD and FPP on the number of days from sowing of the female plants to silking (DS). There was a significant difference $(\mathrm{P}<0.05)$ for number of days from sowing to anthesis of the male plants for MPD. A delay in the MPD was accompanied by an increase in the number of days from sowing to anthesis of the male plants. There was highly significant difference $(\mathrm{P}<0.001)$ for ASI as a result of different male planting dates. ASI ranged from 7 to -15 days for the different MPD. Close synchrony between pollen shed of male inbred lines and silking of the female single cross (ASI $=-3$ days) was observed when male and female plants were sown on the same day. There was no close synchrony between pollen shed of male inbred lines and silking of the female single cross (ASI $=>3$ days or $<3$ days) for all the other male planting dates. FPP and the interaction of MPD and FPP had no observable effect on the ASI for parental components used, as their mean squares were not significant.

Table 1A. Mean square values of main effects of yield and yield components of the female of a three-way hybrid in seed production set up

\begin{tabular}{|c|c|c|c|c|c|c|c|c|c|c|c|}
\hline \multirow{2}{*}{$\begin{array}{l}\text { Source of } \\
\text { variation }\end{array}$} & \multirow[b]{2}{*}{ Df } & \multicolumn{10}{|c|}{ Mean Squares } \\
\hline & & $\begin{array}{l}\text { DS } \\
\text { (days) }\end{array}$ & $\begin{array}{l}\text { DA } \\
\text { (days) }\end{array}$ & $\begin{array}{l}\text { ASI } \\
\text { (days) }\end{array}$ & $\begin{array}{l}\mathrm{PD} \\
\left(\mathrm{m}^{-2}\right)\end{array}$ & $\begin{array}{l}\mathrm{HD} \\
\left(\mathrm{m}^{-2}\right)\end{array}$ & $\begin{array}{l}\text { ED } \\
\left(m^{-2}\right)\end{array}$ & EPP & KPE & $\begin{array}{l}\text { TKW } \\
\text { (g) }\end{array}$ & $\begin{array}{l}\text { GY } \\
\left(\mathrm{t} \mathrm{ha}^{-1}\right)\end{array}$ \\
\hline Block & 2 & $32744^{*}$ & $1022 \mathrm{~ns}$ & $17.24 \mathrm{~ns}$ & $0.973 \mathrm{~ns}$ & $0.829 \mathrm{~ns}$ & $2.188 n$ & $0.017 \mathrm{~ns}$ & $4004.252 \mathrm{~ns}$ & $36630.305^{* * *}$ & $18.161^{* * *}$ \\
\hline MPD & 4 & $4.644 \mathrm{~ns}$ & $51.565^{*}$ & $781.60^{* * *}$ & $0.088 \mathrm{~ns}$ & $0.278 \mathrm{~ns}$ & $0.284 \mathrm{~ns}$ & $0.005 \mathrm{~ns}$ & $129321.602 \mathrm{~ns}$ & $5731.57 \mathrm{~ns}$ & $47.695^{* * *}$ \\
\hline FPP & 2 & $4.642 \mathrm{~ns}$ & $24.503 \mathrm{~ns}$ & $20.36 \mathrm{~ns}$ & $40.649^{* * *}$ & $42.197^{* * *}$ & $27.702^{* * *}$ & $0.103 *$ & $9532.41 \mathrm{~ns}$ & $5125.302 \mathrm{~ns}$ & $18.667^{* *}$ \\
\hline MPD $\times F P P$ & 8 & $5.755 \mathrm{~ns}$ & $11.54 \mathrm{~ns}$ & $14.10 \mathrm{~ns}$ & $0.146 \mathrm{~ns}$ & $0.327 \mathrm{~ns}$ & $0.391 \mathrm{~ns}$ & $0.021 \mathrm{~ns}$ & $6434.618 \mathrm{~ns}$ & $3405.040 \mathrm{~ns}$ & $3.309 \mathrm{~ns}$ \\
\hline Error & 28 & 7198 & 14.591 & 20.148 & 0.35 & 0.325 & 0.709 & 0.021 & 7257.753 & 2507.921 & 3.08 \\
\hline
\end{tabular}

Table 1B. Summary of means of main effects of yield and yield components of the female of three-way hybrid in seed production set up

\begin{tabular}{|c|c|c|c|c|c|c|c|c|c|c|c|}
\hline & Factors & $\begin{array}{l}\text { ASI } \\
\text { (days) }\end{array}$ & $\begin{array}{l}\mathrm{PD} \\
\left(\mathrm{m}^{-2}\right)\end{array}$ & $\begin{array}{l}\mathrm{HD} \\
\left(\mathrm{m}^{-2}\right)\end{array}$ & $\begin{array}{l}\text { ED } \\
\left(m^{-2}\right)\end{array}$ & EPP & KPE & $\begin{array}{l}\text { TKW } \\
\text { (g) }\end{array}$ & $\begin{array}{l}\text { GY } \\
\left(\mathrm{t} \mathrm{ha}^{-1}\right)\end{array}$ & $\begin{array}{l}\text { Yield Mean } \\
(\%)\end{array}$ & Rank \\
\hline \multirow[t]{5}{*}{ MPD } & -10 days & 7 & 4.9 & 4.64 & 4.44 & 1.00 & 202 & 507 & 4.33 & 97 & 3 \\
\hline & -5 days & 2 & 4.8 & 4.33 & 4.45 & 1.02 & 343 & 454 & 6.76 & 151 & 2 \\
\hline & 0 days & -3 & 4.8 & 4.72 & 4.87 & 1.05 & 313 & 451 & 6.81 & 152 & 1 \\
\hline & 5 days & -12 & 5.0 & 4.66 & 4.65 & 1.00 & 120 & 456 & 2.61 & 58 & 4 \\
\hline & 10 days & -15 & 4.8 & 4.79 & 4.53 & 0.99 & 81 & 444 & 1.83 & 40 & 5 \\
\hline \multirow[t]{6}{*}{ FPP } & Low & 3 & 3.1 & 2.86 & 3.17 & 1.11 & 214 & 482 & 3.20 & 72 & 3 \\
\hline & Medium & 4 & 5.0 & 4.81 & 4.71 & 0.98 & 241 & 458 & 5.30 & 119 & 2 \\
\hline & High & 5 & 6.4 & 6.20 & 5.88 & 0.96 & 181 & 446 & 4.90 & 183 & 1 \\
\hline & Grand Mean & 4.2 & 4.85 & 4.654 & 4.604 & 1.010 & 211.8 & 462.2 & 4.466 & 100 & \\
\hline & $\operatorname{LSD}_{(0.05)}$ & 4 & 0.57 & 0.53 & 0.82 & 0.14 & 81 & 48 & 1.70 & & \\
\hline & $\mathrm{CV}$ & 10.5 & 12.1 & 11.8 & 18.4 & 14.5 & 39.6 & 10.8 & 39.3 & & \\
\hline
\end{tabular}

Note. $\mathrm{MPD}=$ male planting date $($ Factor $\mathrm{A}), \mathrm{FPP}=$ female plant population $($ Factor $\mathrm{B}), \mathrm{ASI}=$ anthesis silking interval (days), $\mathrm{EPP}=$ ears per plant, $\mathrm{PD}=$ plant density per square metre, $\mathrm{HD}=$ harvest density per square metre, $\mathrm{ED}=$ ear density per square metre, $\mathrm{KPE}=$ Kernel per ear, TKW $=$ thousand kernel weight, $\mathrm{GY}=$ grain yield (t/ha), $\%$ Mean yield $=\%$ of overall mean yield.

$*, * *, * * *=$ Mean square values significant at $0.05,0.01$ and 0.001 significance levels. $n s=$ Mean square values not significant. 
Female plant density (PD) at emergence was highly significant $(\mathrm{P}<0.001)$ for FPP (Table 1). Female plant density ranged from 3.1 plants $\mathrm{m}^{-2}$ for low FPP, 5.0 plants $\mathrm{m}^{-2}$ for medium FPP and 6.4 plants $\mathrm{m}^{-2}$ for high FPP. There was variation between actual PD and the planned plant density. Planned population was 2.7 to 8.0 plants $\mathrm{m}^{-2}$ but field populations of 3.1 to 6.4 plants $\mathrm{m}^{-2}$ were achieved. Reduction in plant density may be accounted for by destruction of plants during hoe weeding and disease infections. The higher plant density in the low FPD treatment may be accounted for by over planting and ineffective thinning out that was done. There was no significant difference for ear density at harvest for the different MPD and the interaction between the main effects MPD and FPP was also insignificant (Table 1). However ear density was highly significant $(\mathrm{P}<0.001)$ for the different FPP. The highest ear density $\left(5.88\right.$ ears $\left.\mathrm{m}^{-2}\right)$ was noted on medium FPP $\left(5.3\right.$ plants $\left.\mathrm{m}^{-2}\right)$ and the lowest ear density $\left(3.17\right.$ ears $\left.\mathrm{m}^{-2}\right)$ was obtained with low $\operatorname{FPP}\left(8.0\right.$ plants $\left.\mathrm{m}^{-2}\right)$.

FPP were highly significant $(\mathrm{P}<0.001)$ with a range of 2.86 to 6.2 plants $\mathrm{m}^{-2}$ (Table 1$)$. The low population density $\left(2.7\right.$ plants $\left.\mathrm{ha}^{-1}\right)$ had the lowest harvest density $\left(2.86\right.$ plants $\left.\mathrm{m}^{-2}\right)$. Optimum harvest density $(4.81$ plants $\left.\mathrm{m}^{-2}\right)$ was obtained from the medium FPP while the highest FPP $\left(8.0\right.$ plants $\left.\mathrm{m}^{-2}\right)$ had the highest harvest density $\left(6.20\right.$ plants $\left.\mathrm{m}^{-2}\right)$. FPP had a highly significant $(\mathrm{P}<0.001)$ effect on ED of the female plants of the three-way hybrid. The ED ranged from 3.17 to 5.88 ears $\mathrm{m}^{-2}$ for the female plant population of the three-way hybrid. The highest ED for the FPP was obtained on high FPP $\left(5.88 \mathrm{t} \mathrm{ha}^{-1}\right)$ while the lowest ED (3.17) was obtained on low FPP. FPP had a significant $(\mathrm{P}<0.05)$ effect on the number of ears per plant $(\mathrm{EPP})$ of the female plants of the three-way hybrid. EPP ranged from 0.96 to 1.11 for the different FPP, with the high female population density $\left(8.0\right.$ plant $\left.\mathrm{m}^{-2}\right)$ having the lowest average EPP $(0.96)$ and the lowest female population density $\left(2.7\right.$ plants $\left.\mathrm{m}^{-2}\right)$ having the highest average EPP (1.11).

The highest KPE (241 kernels) was noted for medium FPP while the lowest number of kernels was noted for high FPP.

Grain yield was highly significant $(\mathrm{P}<0.001)$ for MPP, with yields ranging from 1.83 to $6.81 \mathrm{t} \mathrm{ha}^{-1}$. FPP was significant $(\mathrm{P}<0.01)$ for grain yield with the highest yield $\left(5.30 \mathrm{t} \mathrm{ha}^{-1}\right)$ being obtained for medium FPP (5.3 plants $\left.\mathrm{m}^{-2}\right)$ and the lowest yield $\left(3.20 \mathrm{t} \mathrm{ha}^{-1}\right)$ obtained for low FPP $\left(2.7\right.$ plants $\left.\mathrm{m}^{-2}\right)$. However, the interaction for the two factors was not significant for grain yield.

\subsection{Relationship between Grain Yield and Other Traits and treatments of Main Effects}

ASI affected the grain yield of the female of the three-way hybrid as a result of varying MPD. Likewise, grain yield was also affected by FPP. The cumulative emergence of silks on the female and the cumulative proportion of plants shedding pollen for each MPD treatment are shown in Figure 1. A short ASI is considered optimum for kernel set in hybrid seed maize production. Ideally, the male plants should begin shedding pollen when the first female silks begin appearing. The time to $50 \%$ silking of the female plants occurred 75 days after planting and the time to $50 \%$ pollen shedding of male plants ranged from 67 days to 90 days after planting of the male. Data for DA and DS showed that ASI ranged from 7 days to -15 days. An almost perfect nick was obtained at MPD day zero where ASI $=-1$.

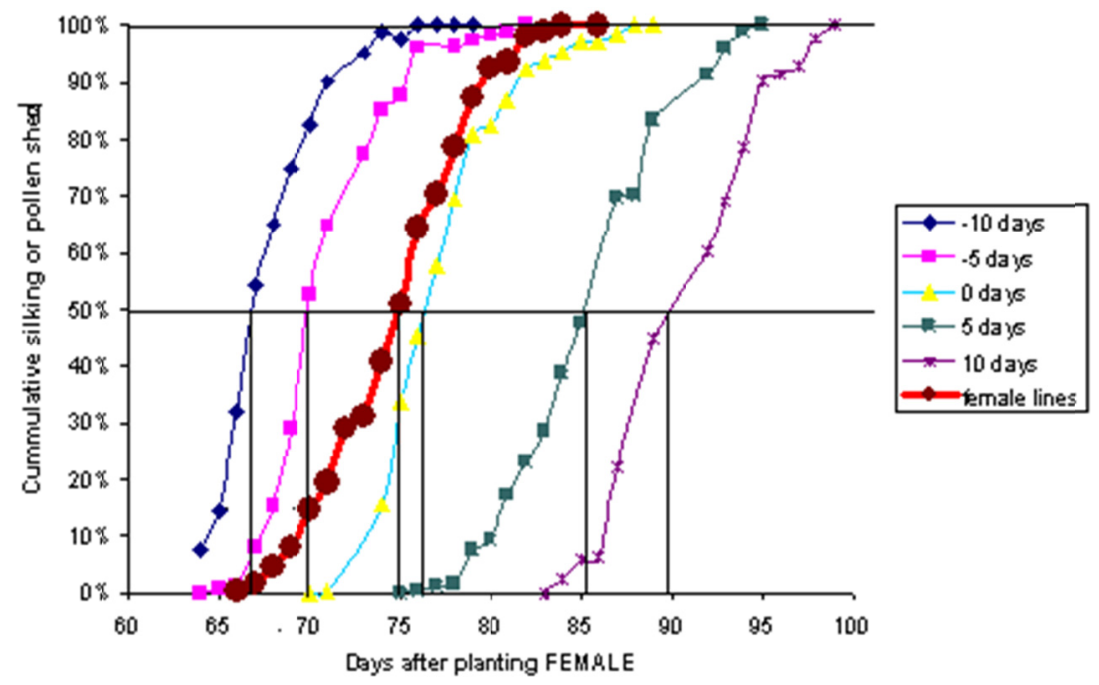

Figure 1. Relationship between cumulative silking or pollen shed and days after planting females 
The relationship between GY and ASI showed that GY was greatest $\left(6.81 \mathrm{tha}^{-1}\right)$ where there was close synchrony between pollen shed of male plants and silking of the female single cross (ASI $=+/-3$ days) (Figure not presented). GY was less when ASI was either less than three days or greater than three days. A significant curvilinear regression was obtained between GY and ASI $\left(\mathrm{R}^{2}=0.94\right)$.

The relationship between GY and female plant density (FPD) is presented in Figure 2 and a quadratic equation was fitted to the data. As plant density increased from a low FPP of 3.1 plants $^{-2}$ to a medium FPP of 5.0 plants $\mathrm{m}^{-2}$, there was a corresponding increase in GY from $3.20 \mathrm{t} \mathrm{ha}^{-1}$ to $5.30 \mathrm{t} \mathrm{ha}^{-1}$. Yield declined from the medium FPP to the high FPP of 6.4 plants $\mathrm{m}^{-2}$. Based on the curvilinear relationship the estimated maximum GY was obtained at a FPP of 5.4 plants $\mathrm{m}^{-2}$.

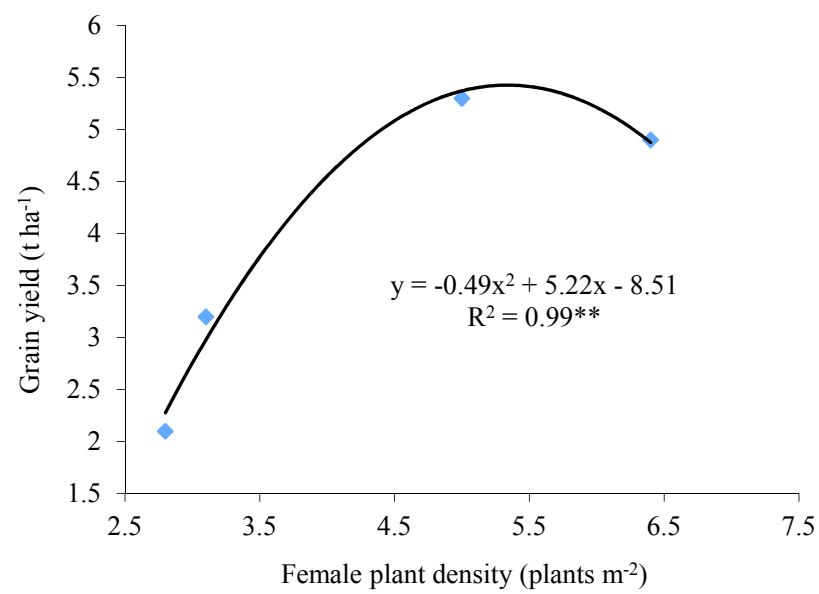

Figure 2. Relationship between grain yield and female plant density

The relationship between grain yield and female harvest density showed that lowest grain yields were noted for low HD ( 3 plants $\left.\mathrm{m}^{-2}\right)$ for all MPD with the exception of MPD +10 days where the highest HD $\left(6\right.$ plants $\left.\mathrm{m}^{-2}\right)$ had the lowest yield of $\left(0.9 \mathrm{t} \mathrm{ha}^{-1}\right)$ (Figure not presented). Increased HD from low to medium HD resulted in a corresponding increase in GY. A general decline in GY was noted with further increase in HD from medium to high HD $\left(6\right.$ plants $\left.\mathrm{m}^{-2}\right)$ with the exception of MPD of -5 and +5 days where there was a continuous increased grain yield of 8.07 and $3.70 \mathrm{t} \mathrm{ha}^{-1}$ respectively. Harvest density may also be related to the linear relationship between PD at emergence and ED at harvest (Figure not presented). This explains the general relationship of GY and HD. A positive correlation $\left(\mathrm{R}^{2}=0.97\right)$ between PD at emergence and plant or ear density at harvest was noted. At low FPP, ED was greater than HD, while at high FPP, ED was less than HD.

Yield components may help to understand variation in GY of seed maize across environments. Yield components of the female of the three-way hybrid in relation to PD, ASI, EPP, KPE and TKW varied as a function of MPD and FPP.

The relationship between ED and GY showed a positive correlation $\left(\mathrm{R}^{2}=0.97\right)$, which showed that an increase in ED resulted in a corresponding increase in GY (Figure not presented). Maximum GY (5.3 tha ${ }^{-1}$ ) was obtained

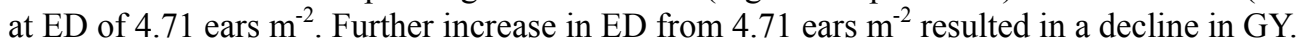

A negative correlation $\left(\mathrm{R}^{2}=0.53\right)$ between EPP and PD at emergence showed that an increase in PD at emergence resulted in a corresponding decline in EPP (Figure not presented). An increase in PD at emergence from 3.1 plants $\mathrm{m}^{-2}$ to 5.0 plants $\mathrm{m}^{-2}$ resulted in a decline in EPP from 1.11 to $0.98 \mathrm{ears}^{-2}$. Further increase in $\mathrm{PD}$ at emergence to 6.20 ears $\mathrm{m}^{-2}$ resulted in a continuous decline of EPP to 0.96 ears $\mathrm{m}^{-2}$.

The quadratic equations fitted to the data on relationship between GY and FPD for the two FPP (high and medium) showed that there was a significant correlation $\left(R^{2}=0.97\right)$ between grain yield and female planting date for high $\left(8.0\right.$ plants $\left.\mathrm{m}^{-2}\right)$ and medium $\left(5.3\right.$ plants $\mathrm{m}^{-2}$ ) FPP, respectively (Figure 3). GY was greatest for high FPP as compared to medium FPP. Quadratic equation for low FPP is missing, as the simulation model could not deal with low population density $\left(2.7\right.$ plants $\left.\mathrm{m}^{-2}\right)$. 


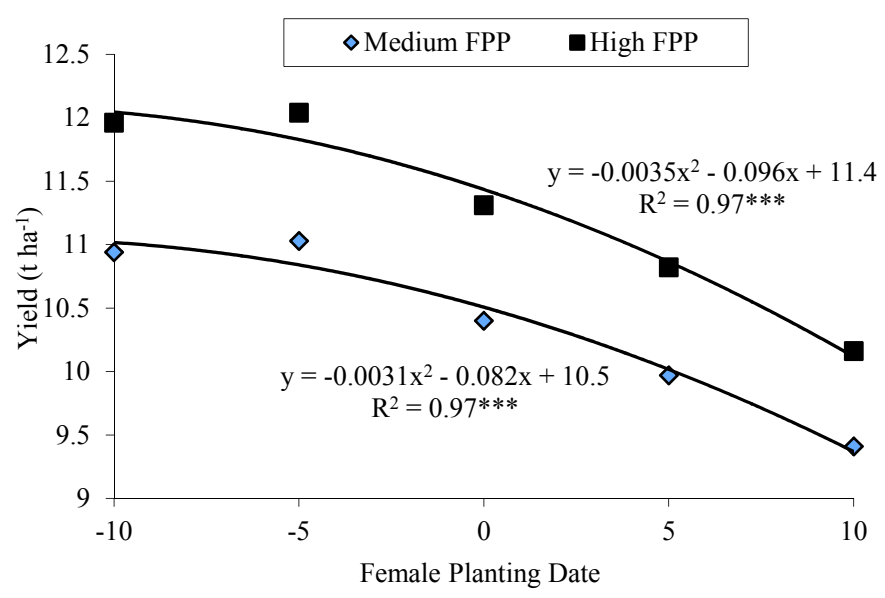

Figure 3. Relationship between grain yield and female planting date

\subsection{Simulation Output for Hybrid-Maize Simulation Model}

Hybrid-Maize simulation model simulates the growth and yield of maize so as to enable the evaluation of grain yield using different combinations of planting date and plant density. The greatest yield of $12.04 \mathrm{t} \mathrm{ha}^{-1}$ was noted for high FPP (80 000 plants ha $\left.^{-1}\right)$ (Table 2) and the data showed that the general trend was that the greatest yield was obtained for high FPP for the entire female planting dates. The model could not deal with low FPP (2.7 plants $\mathrm{m}^{-2}$ ) resulting in missing output that was noted for the simulation model output. The model could also not cope with a hybrid seed field situation of male and female planting dates, which are different. As a result FPD used in this trial were assumed to be MPD. Thus, FPD in the model was used to estimate GY.

Table 2. Grain yield output for the Hybrid-Maize simulation model

\begin{tabular}{|c|c|c|c|}
\hline \multirow{2}{*}{ 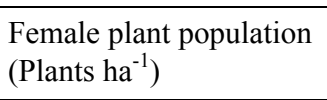 } & \multirow{2}{*}{ Female planting date } & \multicolumn{2}{|c|}{ Simulated yield $\left(\mathrm{t} \mathrm{ha}^{-1}\right)$} \\
\hline & & Grain yield $\left(\mathrm{t} \mathrm{ha}^{-1}\right)$ & Rank \\
\hline 80000 & $13 / 10 / 06$ & 11.96 & 2 \\
\hline 53333 & & 10.94 & 5 \\
\hline 26666 & & $*$ & . \\
\hline 80000 & $18 / 10 / 06$ & 12.04 & 1 \\
\hline 53333 & & 11.03 & 4 \\
\hline 26666 & & $*$ & . \\
\hline 80000 & $23 / 10 / 06$ & 11.31 & 3 \\
\hline 53333 & & 10.40 & 7 \\
\hline 26666 & & $*$ & . \\
\hline 80000 & $28 / 10 / 06$ & 10.82 & 6 \\
\hline 53333 & & 9.97 & 9 \\
\hline 26666 & & $*$ & . \\
\hline 80000 & $2 / 11 / 06$ & 10.16 & 8 \\
\hline 53333 & & 9.41 & 10 \\
\hline 26666 & & $*$ & . \\
\hline
\end{tabular}

Note. * Missing data from output.

\subsection{Comparison of Predicted Yield and Observed Yield}

Comparison of model predicted grain yield and observed grain yield (Figure 4) showed that there was an over estimation of predicted versus the observed yield. At low observed yield there was a high-predicted yield. 


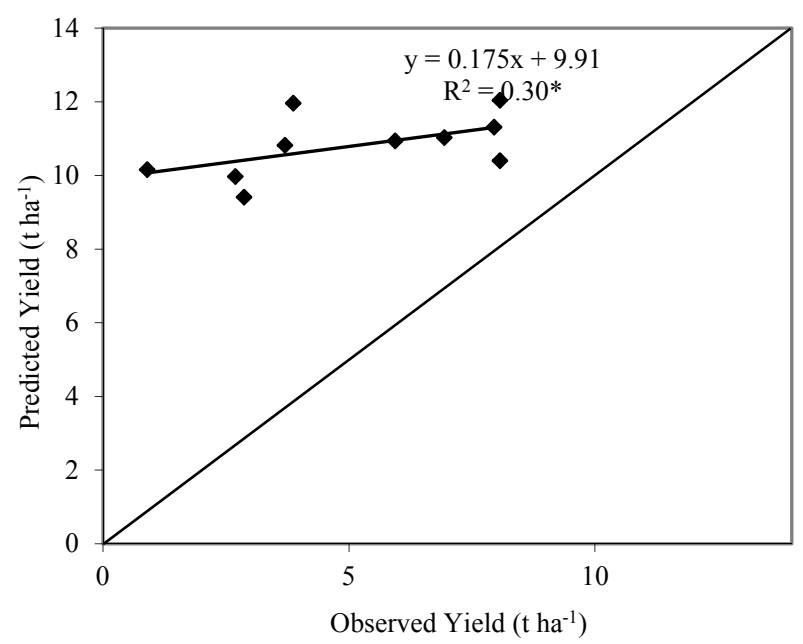

Figure 4. Comparison of predicted yield and observed yield of the maize three-way hybrid

\section{Discussion}

A short ASI is a key trait for obtaining high grain yield in maize seed production (Bolanos \& Edmeades, 1993). It is the same case in hybrid maize production where female plants are totally dependant on male plants for the supply of pollen. In this experiment, a shift in the interval from close synchrony (+/-3 days) was associated with a decline in GY for the female of the three-way hybrid. Similar results were documented in reports by Bolanos and Edmeades (1993), and Edemeades et al. (2000). An increased ASI could reduce kernel number because of lack of pollen for late-appearing silks while early appearing silks may have reduced receptivity to the pollen. A shift in ASI from close synchrony reduced grain yield. Close synchrony between pollen shed of male and silking of female (ASI $=+/-3$ days) gave the greatest yield. There are two possible reasons for such a significant enhancement in grain yield: i) a much larger fraction of late-emerging silks are pollinated when pollen shed is delayed relative to silking hence there is prolongation of the effective flowering period; and ii) all the early emerging silks are pollinated as well because they remain receptive to pollen for several days after they appear (Bassetti \& Westgate, 1993a, 1993b). This showed that timing of silking of the female population in relation to pollen shed of male population is a crucial management variable in hybrid seed production as it impact on potential grain yield as evidenced by the highly significant variability in grain yield for ASI. These results are similar to findings by Edemeades et al. (2000), and Bolanos and Edmeades (1993), showing significant increase in ASI when plants were exposed to drought during the time bracketing flowering and consequently causing reduction in GY.

Delaying pollen shed to maximize pollination by late planting of male line (MPD $=+5$ and +10 days) did not increase GY but increased the potential risk of out-crossing from foreign pollen sources. This was contrary to literature: Fonseca et al (2004) using simulated data reported that delaying pollen shed from the original 1.2 to 3 days resulted in nearly $68 \%$ of the silks being pollinated causing a $23 \%$ increase in potential kernel yield. If the interval were increased to 5 days, potential kernel yield would be increased by about $38 \%$, indicating the potential of increasing GY by late planting of male line. Hence, the best approach to managing floral synchrony will depend on the time from planting to pollen shed and silking of the respective parents.

Maize is sensitive to intra-specific competition as evidenced by the highly significant effect of FPP on GY. Stand density affects plant architecture, alters growth and developmental patterns and influences carbohydrates production and partition. Increased FPP from low $\left(3.1\right.$ plants $\left.\mathrm{m}^{-2}\right)$ to medium $\left(5.30 \mathrm{plants}^{-2}\right)$ density resulted in increased yield. A further increase in FPP from medium to high $\left(6.4\right.$ plants $\left.\mathrm{m}^{-2}\right)$ resulted in a decline in GY in agreement with reports by Edmeades and Daynard (1979a), Tetiokago and Gardner (1988), Echarte et al. (2000), and Sangoi et al. (2002). For each production system there is a population that maximizes the utilization of available resources, allowing the expression of maximum attainable GY on the environment. In this work, optimum density was noted from the regression equation to be 5.4 plants $\mathrm{m}^{-2}$. When the number of individual plants per unit area was increased beyond this optimum density, there was a series of consequences that were detrimental to ear ontogeny and resulted in barrenness hence the decline in GY (Sangoi et al., 2002).

Decline in GY when plant density increased beyond the optimum density is usually associated with a decline in the harvest index and increased stem lodging caused by increase in inter-plant competition for solar radiation, 
soil nutrients and soil water (Tollenaar et al., 2000). This also results in limited supplies of photosynthetic photon flux density, carbon and soil nutrients and consequently increases barrenness and decreases kernel number per plant, kernel size and kernel weight. Edmeades et al. (2000) also reported interplant and intraplant competition affecting ASI as the underlying cause of the significant reduction in GY. Intraplant competition may exist between ear and stem or root growth resulting in significant decline in GY.

\subsection{Relationship between Grain Yield, Harvest Density and Other Yield Components}

Relationship between GY and HD showed that as HD increased there was an increase in GY and GY showed a response to HD that produced maximum value at the optimum HD. At low HD, grain yield was not compensated by increased KPE, TKW or EPP while substantial low EPP occurred above the optimum HD (Tetiokago \& Gardener, 1988). However, exceptions were observed in this experiment contrary to other reports in literature. A continuous increase in grain yield as HD increased from medium to high for MPD ( -5 and +5$)$ was noted. This could be accounted for by the fact that increased HD was used as an efficient management tool for maximizing grain yield by increasing the capture of solar radiation within the canopy for the two MPD. The linear relationship between the GY and HD was further explained by the linear relationship between plant density at emergence and plant or ear density at harvest. As plant density increased at emergence a corresponding increase in the number of plants or ears harvested at maturity was noted. This was contrary to a report by Sangoi et al. (2002), which showed that high rates of planting slowed the rates of axillary buds more than they do the shoot apex.

Grain yield and its components: EPP, KPE and TKW showed a dependence on the ASI. According to a report by Edmeades et al. (2000), GY and its component: KPE, show a dependence on ASI of the general form GY = $\exp ^{\left(\mathrm{a}+\mathrm{b}^{* A S I}\right)}$. In this experiment, for all measured yield components there was a general significant reduction in GY with increase in main effects of MPD and FPP.

\subsection{Relationship between Plant Density at Emergence and Ears per Plant}

An increase in PD at emergence resulted in a corresponding decline in EPP; the linear relationship indicated negative correlation $\left(\mathrm{R}^{2}=0.53\right)$, being noted in agreement with some reports in literature (Edmeades \& Daynard, 1979). According Edmeades and Daynard (1979) as plant density is increased, the ratio of ear growth rate (i.e. rachis + developing grain) to total shoot growth declines drastically. This decline can be attributed largely to decline in radiation reaching the ear leaf at high densities relative to low and medium population densities. The ear leaf provides a large proportion of assimilates to the ear. An unfavourable environmental condition through intraplant competition reduces dry matter partitioning from the ear leaf to the ear resulting in cessation of ear development and ear abortion. This is illustrated in this work by the reduction in EPP with an increase in PD at emergence. High plant densities produced low plant growth rate (PGR), whereas low plant densities induced high PGR.

\subsection{Simulation Output for Hybrid-Maize Simulation Model}

Contrary to several reports (Jones \& Kiniry, 1986; Yang et al., 2006) Hybrid-Maize simulation model had an overestimation of GY potential of the female of the three-way hybrid for high and medium FPP. Greatest GY was noted for high FPP $\left(12.04 \mathrm{tha}^{-1}\right)$. Delay in the female planting date resulted in a decline in yield for the two FPP as a result of reduced growing season for the late planted female population and also due to reduced grain filling period. An over estimate of the actual yield was also noted from the simulation output which might be due to the fact that the Hybrid-Maize simulation model did not take into account other limiting factors during the run of the season, which might have also reduced the potential yield. Its inability to separate male and female planting dates in seed production is another factor that might have contributed to an over estimation of the actual yield. The assumption from the model is that there is no limitation in pollen density and timing of pollen shed, which is contrary to variation brought about by the MPD and use of a male inbred line. The inability of the simulation model to estimate yield for low FPP $\left(2.7\right.$ plants $\left.\mathrm{m}^{-2}\right)$ is another limitation the model has for simulating hybrid maize seed production.

\section{Conclusion}

Female seed yield was affected by time of male pollen shed relative to female silking (ASI), with highest yields associated with close synchrony (ASI $=+/-3$ days). Also, female seed yield was greatest at medium FPP of 5.4 plants $\mathrm{m}^{-2}$. ASI had a significant effect on KPE, with the greatest KPE (318) associated with close synchrony (ASI $=+/-3$ days). Specific optimum plant density and male planting dates in relation to the female for hybrids should be determined to attain maximum GY in maize seed production.

From this study we found that Hybrid-Maize simulation model has limited potential for simulating hybrid maize seed production, as it does not accommodate limitations that may occur during the growing season: difference in 
male and female planting dates and pollen density and dispersion. Hence, the fixed parameters for the Hybrid-Maize simulation model can only be used in maize commercial production.

Simulation of maize grain yield in hybrid maize seed production can only be done if the model has the ability to:

a) Deal separately with male and female planting dates.

b) Determine pollen flow from male plants to female plants.

c) Deal with variation of population ratio for both male and female parents.

We suggest that seed producing companies may use the Hybrid-Maize simulation model to determine the yield potential of three-way hybrids, taking other factors of production constant except low female population density.

\section{Acknowledgements}

The authors are grateful to CIMMYT, its staff and collaborators for the financial and technical support.

\section{References}

Agronomix Software Inc. (2007). Agro-base GII Statistical Package.

Andrade, F. H., Calvino, P., Cirilo, A., \& Barbieri, P. (2002). Yield responses to narrow rows depend on increased radiation interception. Agron. J., 94, 975-980. https://doi.org/10.2134/agronj2002.9750

Andrade, F. H., Vega, C., Uhart, S. A., Cirilo, A., Cantarero, M., \& Valentinuz, O. (1999). Kernel number determination in maize. Crop Sci., 39, 453-459. https://doi.org/10.2135/cropsci1999.0011183X0039000 $200026 x$

Bassetti, P., \& Westgate, M. E. (1993a). Emergence, elongation and senescence of maize silks. Crop Sci., 33, 275-278. https://doi.org/10.2135/cropsci1993.0011183X003300020011x

Bassetti, P., \& Westgate, M. E. (1993b). Senescence and receptivity of maize silks. Crop Sci., 33, $275-278$. https://doi.org/10.2135/cropsci1993.0011183X003300020012x

Bolanos, J., \& Edmeades, G. O. (1993). Eight cycles of selection for drought tolerance in lowland tropical maize. II. Response in reproductive behaviour. Field Crops Res., 31, 253-268. https://oi.org/10.1016/ 0378-4290(93)90065-U

Carcova, J., Uribelarrea, M., Borras, L., Otegui, M. E., \& Westgate, M. E. (2002). Synchronization pollination within and between ears improves kernel set in maize. Crop Sci., 40, 1056-1061. https://oi.org/10.2135/ cropsci2000.4041056x

Echarte, L., Luque, S., Andrade, F. H., Sandras, V. O., Cirilo, A., Otegui, M. E., \& Vega, C. R. C. (2000). Response of maize kernel number to plant density in Argentinean hybrids released between 1963 and 1993. Field Crops Res., 68, 1-8. https://doi.org/10.1016/S0378-4290(00)00101-5

Edmeades, G. O., \& Daynard, T. B. (1979). The development of plant-to-plant variability in maize at different densities. Can. J. Plant Sci., 59, 561-576. https://doi.org/10.4141/cjps79-095

Edmeades, G. O., Banziger, M., \& Ribaut, J. M. (2000). Maize improvement for drought-limited environments. In M. E. Otegui \& G. A. Slafer (Eds.), Physiological bases for maize improvement (pp. 75-111). Food Products Press, The Haworth Press, New York.

Fonseca, A. E., Lizaso, J. I., Westgate, M. E., Grass, L., \& Dornobos, D. L. (2004). Simulating potential kernel production in maize hybrid seed fields. Crop Sci., 44, 1696-1700. https://doi.org/10.2135/cropsci2004.1696

Havazvidi, E. K., \& Tatterfield, R. J. (2006). Development of the seed industry. In M. Rukuni, P. Tawonezvi, \& C. Eicher (Eds.), Zimbabwe's Agricultural Revolution Revisited (pp. 235-253). University of Zimbabwe Publications, Harare.

Jones, C. A., \& Kiniry, J. R. (1986). CERES-Maize: A simulation model of maize growth and development. Texas A\&M Univ. Press, College Station.

Lizaso, J. I., Westgate, M. E., Batchelor, W. D., \& Fonseca, A. (2003). Predicting potential kernel set in maize from simple flowering characteristics. Crop Sci., 43, 892-903. https://doi.org/10.2135/cropsci2003.8920

Rosegrant, M. W., Agcaoili-Simbilla, A., \& Perez, N. D. (1995). Global food projections to 2020: Implications for investment. Food, Agriculture, and the Environment Discussion Paper No. 5. International Food Policy Research Institute, Washington, D.C. USA. 
Sangoi, L., Gracietti, M. A., Rampazzo, O., \& Biancheti, P. (2002). Response of Brazilian maize hybrids from different eras to changes in plant density. Field Crops Res., 79, 39-51. https://doi.org/10.1016/ S0378-4290(02)00124-7

Sarquis, J. I., Gonzalez, H., \& Dunlap, J. R. (1998). Yield response of two cycles of selection from a semi prolific early maize population to plant density, sucrose infusion and pollination control. Field Crops Res., 55, 109-116. https://doi.org/10.1016/S0378-4290(97)00071-3

Saseendran, S. A., Hubbard, K. K., Singh, N., Mendiratta, L. S., Rathole, P. M., \& Singh, S. V. (2005). Transplanting dates for rice in Kerala, India using CERES and ClimProb. Agron. J., 90, 185-190. https://doi.org/10.2134/agronj1998.00021962009000020011x

Tetiokago, F., \& Gardner, F. P. (1988). Response of maize to plant population density. I. Canopy development, light relationships, and vegetative growth. Agron. J., 80, 930-935. https://doi.org/10.2134/agronj1988. $00021962008000060018 x$

Tollenaar, M., Dwyer, L. M., Stewart, D. W., \& Ma, B. L. (2000). Physiological parameters associated with differences in kernel set among maize hybrids. In M. A. Westgate \& K. J. Boote (Eds.), Physiology and modeling kernel set in maize (pp. 115-130). CSSA/ASA/SSSA, Madison, WI.

Tripp, R. (2001). Seed Provision and Agricultural Development. Heinemann, Portsmouth.

Yang, H. S., Dobermann, A., Lindiquist, J. L., \& Walters, D. T. (2006). Hybrid-Maize: A simulation model that combines two crop modeling approaches. Dept of Agronomy and Horticulture, University of Nebraska-Lincoln, USA.

\section{Copyrights}

Copyright for this article is retained by the author(s), with first publication rights granted to the journal.

This is an open-access article distributed under the terms and conditions of the Creative Commons Attribution license (http://creativecommons.org/licenses/by/4.0/). 